\title{
G9a/GLP-dependent histone H3K9me2 patterning during human hematopoietic stem cell lineage commitment
}

\author{
Xiaoji Chen, ${ }^{1,2}$ Kyobi Skutt-Kakaria, ${ }^{2,3}$ Jerry Davison, ${ }^{4}$ Yang-Li Ou, ${ }^{2}$ Edward Choi, ${ }^{5}$ Punam Malik, ${ }^{6}$ \\ Keith Loeb, ${ }^{5}$ Brent Wood, ${ }^{7}$ George Georges, ${ }^{5}$ Beverly Torok-Storb, ${ }^{5}$ and Patrick J. Paddison ${ }^{1,2,8}$ \\ ${ }^{1}$ Molecular and Cell Biology (MCB) Program, ${ }^{2}$ Human Biology Division, Fred Hutchinson Cancer Research Center, Seattle, \\ Washington 98109, USA; ${ }^{3}$ The Evergreen State College, Olympia, Washington 98505, USA; ${ }^{4}$ Public Health Sciences Division, \\ ${ }^{5}$ Clinical Research Division, Fred Hutchinson Cancer Research Center, Seattle, Washington 98109, USA; ${ }^{6}$ Division \\ of Experimental Hematology, Cancer and Blood Diseases Institute, Cincinnati Children's Hospital Medical Center, Cincinnati, \\ Ohio 45229, USA; ${ }^{7}$ Seattle Cancer Care Alliance, Fred Hutchinson Cancer Research Center, Seattle, Washington 98109, USA
}

G9a and GLP are conserved protein methyltransferases that play key roles during mammalian development through mono- and dimethylation of histone $\mathrm{H} 3 \mathrm{Lys} 9$ (H3K9me1/2), modifications associated with transcriptional repression. During embryogenesis, large $\mathrm{H} 3 \mathrm{~K} 9 \mathrm{me} 2$ chromatin territories arise that have been proposed to reinforce lineage choice by affecting high-order chromatin structure. Here we report that in adult human hematopoietic stem and progenitor cells (HSPCs), H3K9me2 chromatin territories are absent in primitive cells and are formed de novo during lineage commitment. In committed HSPCs, G9a/GLP activity nucleates H3K9me2 marks at CpG islands and other genomic sites within genic regions, which then spread across most genic regions during differentiation. Immunofluorescence assays revealed the emergence of $\mathrm{H} 3 \mathrm{~K} 9 \mathrm{me} 2$ nuclear speckles in committed HSPCs, consistent with progressive marking. Moreover, gene expression analysis indicated that G9a/GLP activity suppresses promiscuous transcription of lineage-affiliated genes and certain gene clusters, suggestive of regulation of HSPC chromatin structure. Remarkably, HSPCs continuously treated with UNC0638, a G9a/GLP small molecular inhibitor, better retain stem cell-like phenotypes and function during in vitro expansion. These results suggest that G9a/GLP activity promotes progressive H3K9me2 patterning during HSPC lineage specification and that its inhibition delays HSPC lineage commitment. They also inform clinical manipulation of donor-derived HSPCs.

[Keywords: G9a; GLP; H3K9me2; UNC0638; differentiation; hematopoietic stem and progenitor cell]

Supplemental material is available for this article.

Received July 5, 2012; revised version accepted September 28, 2012.

G9a/EHMT2 and GLP/EHMT1 are conserved protein lysine methyltransferases that play key roles in regulating gene expression and chromosome structure during mammalian development through de novo mono- and dimethylation of histone $\mathrm{H} 3$ Lys 9 (H3K9me1/2) (for review, see Collins and Cheng 2010), histone marks associated with transcriptional silencing (Litt et al. 2001; Noma et al. 2001; Su et al. 2004; Wen et al. 2009). G9a and GLP contain nearly identical Su(var)3-9 family SET methyltransferase domains, with which they bind and methylate $\mathrm{H} 3 \mathrm{~K} 9 \mathrm{me} 0 / 1$, and ankyrin repeat domains that create a methyl-lysine-binding module that allows binding of H3K9me1/2 marks separately from their catalytic domains

${ }^{8}$ Corresponding author

E-mail paddison@fhcrc.org

Article published online ahead of print. Article and publication date are online at http://www.genesdev.org/cgi/doi/10.1101/gad.200329.112.
(Collins et al. 2008). Thus, G9a and GLP have separable "reading" and "writing" functions and can "read" their own marks, which may allow nucleation and spreading of H3K9me2 marks along chromatin, although to our knowledge, this has not been demonstrated in mammals (Collins and Cheng 2010).

G9a is essential for early mouse embryo development and embryonic stem cell (ESC) differentiation (Tachibana et al. 2002). Its loss abolishes methylated H3K9 in euchromatic regions (Tachibana et al. 2002; Rice et al. 2003). However, H3K9 trimethylation (H3K9me3) (Peters et al. 2003), a transcriptional repressive mark found in heterochromatic regions, is unaffected by G9a loss and is maintained by other methyltransferases; e.g., Suv39h or Setdb1 (Peters et al. 2003; Rice et al. 2003). G9a and H3K9me2 have been associated with euchromatic gene silencing in several cellular contexts: silencing of Oct4 gene in differentiating mouse ESCs (Feldman et al. 2006), NRSF/REST-mediated 
silencing of neuronal genes in nonneuronal lineages (Roopra et al. 2004), and PRDI-BF1-mediated silencing during B-cell differentiation (Gyory et al. 2004). The H3K9me2 mark can be found in isolated regions near genes and also in large megabase chromatin blocks that can be lineage-specific and/or lost in cancer cell lines, which may be indicative of structural roles in maintaining epigenetic memory during lineage formation (Wen et al. 2009). However, precise roles for G9a/GLP-H3K9me2 patterning in somatic cells or somatic stem cell selfrenewal and lineage commitment have yet to be established.

The mammalian hematopoietic system is hierarchically organized such that the developmental potential to produce lineages and terminally differentiated cells is progressively restricted (Supplemental Fig. S1; Doulatov et al. 2012). However, our understanding of the molecular events controlling hematopoietic stem cell (HSC) fate decisions is only just emerging (Orkin and Zon 2008), and methods to control stem cell fate remain elusive. This has significantly limited the successful application of HSC transplantation for patients with cancer, marrow failure, hemoglobinopathies, autoimmune diseases, or any other clinical condition that could benefit from an infusion of HSCs or their progeny.

Here, we examined H3K9me2 patterning in normal human hematopoietic stem and progenitor cells (HSPCs). We show that G9a/GLP activity drives progressive, genomewide $\mathrm{H} 3 \mathrm{~K} 9 \mathrm{me} 2$ patterning in euchromatin during HSPC lineage specification. Remarkably, HSPCs treated with UNC0638, a G9a/GLP small molecular inhibitor (Vedadi et al. 2011), altered $\mathrm{H} 3 \mathrm{~K} 9 \mathrm{me} 2$ marks to better resemble those observed in primitive $\mathrm{CD} 34^{+} \mathrm{CD} 90^{+} \mathrm{CD} 38^{10} \mathrm{CD} 45 \mathrm{RA}^{-}$ HSCs. UNC0638-treated HSPCs also better retain stem cell-like phenotypes and function during in vitro expansion. Moreover, cotreatment of HSPCs with UNC0638 and SR1, a small molecular inhibitor of the aryl hydrocarbon receptor (AHR), recently shown to promote expansion of human HSPCs (Boitano et al. 2010), resulted in further expansion of adult $\mathrm{CD} 34^{+}$cells. Our findings suggest that G9a/GLP-mediated $\mathrm{H} 3 \mathrm{~K} 9 \mathrm{me} 2$ patterning is involved in critical steps during HSPC lineage commitment and that its inhibition leads to delayed differentiation and retention of the primitive HSPCs.

\section{Results}

G9a/GLP-mediated H3K9me2 patterning is progressive during HSPC lineage commitment and reversed by UNC0638 treatment

To investigate roles for G9a and GLP methyltransferase function during human HSPC lineage specification, we first examined global chromatin $\mathrm{H} 3 \mathrm{~K} 9 \mathrm{me} 2$ patterning using chromatin immunoprecipitation (ChIP) (O'Geen et al. 2011). To this end, H3K9me2 ChIP sequencing (ChIP-seq) analysis was performed on the following cell populations: HSC-enriched $\mathrm{CD} 34^{+} \mathrm{CD} 90^{+} \mathrm{CD} 38^{\mathrm{lo}} \mathrm{CD} 45 \mathrm{RA}{ }^{-}$ cells (Majeti et al. 2007), unfractionated CD34 ${ }^{+}$cells (which contain mainly committed progenitors), $\mathrm{CD} 41^{+} \mathrm{CD} 61^{+}$ committed megakaryocytes (Megs) (Novershtern et al.
2011), CD3 ${ }^{+} \mathrm{T}$ cells (Majeti et al. 2007), and the HS-5 human bone marrow stromal cell line (Fig. 1; Graf et al. 2002).

To ensure that H3K9me2 ChIP-seq peaks were specific to H3K9me2 and G9a/GLP activity, in control ChIP-seq experiments in unfractionated CD $34^{+}$cells, we used a recently developed chemical probe, UNC0638, which potently and selectively inhibits both G9a and GLP methyltransferase activity by blocking substrate access to their SET methyltransferase domains (Vedadi et al. 2011).

The ChIP-seq analysis revealed an unexpected series of results (Fig. 1). The most primitive HSCs displayed small and fewer $\mathrm{H} 3 \mathrm{~K} 9 \mathrm{me} 2$ peaks. Unfractionated $\mathrm{CD} 34^{+}$cells, containing mainly committed progenitors, showed higher, defined peaks that generally occur at $\mathrm{CpG}$ islands (CGIs). In differentiated Megs and T cells, peaks arising in CD34 ${ }^{+}$ cells were elaborated on and expanded to form nearly identical H3K9me2 territories in genic regions. Figure 1A and Supplemental Figure S2A show representative samples of $80 \mathrm{~kb}$ of chromosome 11 and chromosome 19 from the ChP-seq data. Virtually all genic regions showed a similar pattern.

Evidence for this pattern arose from multiple analyses of the ChIP-seq data. First, the frequency of sequence reads per $\mathrm{H} 3 \mathrm{~K} 9 \mathrm{me} 2$ peak (when examining either peak height or width) showed progressive increases from more primitive to differentiated cells, which were blocked and reversed by UNC0638 treatment of CD34 ${ }^{+}$HSPCs (Fig. 1B; Supplemental Fig. S2B).

Second, examination of the $\mathrm{H} 3 \mathrm{~K} 9 \mathrm{me} 2$ peaks arising in CD34 ${ }^{+}$HSPCs revealed $\sim 95 \%$ overlap peaks in Megs and $\mathrm{T}$ cells (Fig. 1C-E). Figure 1D shows this result for the entirety of chromosome 11 using a hive plot representation, where green lines show H3K9me2 marks shared between HSPCs, Megs, and T cells, and red lines show marks that have expanded in Megs and $\mathrm{T}$ cells. The results show that almost all H3K9me2 marks found in HSPCs are transmitted to Megs and T cells. Hive plots for other chromosomes showed identical results (Supplemental Fig. S2C; data not shown).

Third, another dramatic result revealed in the hive plots was that there are no lineage-specific $\mathrm{H} 3 \mathrm{~K} 9 \mathrm{me} 2$ patterns transmitted from HSPCs to Megs or from HSPCs to $\mathrm{T}$ cells. These patterns would appear as purple lines between HSPCs and Megs or HSPCs and T cells. This was true for all other chromosomes as well (Supplemental Fig. S2C; data not shown). This notion is supported by correlation of peak overlaps in different populations: Megs and $\mathrm{T}$ cells share $>90 \%$ of overlap (Fig. 1E). These analyses support a model for H3K9me2 patterning in HSPC differentiation that is progressive but not lineage-specific, at least within the cell types we examined. However, further analysis of other lineages needs to be done to confirm that $\mathrm{H} 3 \mathrm{~K} 9 \mathrm{me} 2$ patterning is not lineage-specific.

Fourth, H3K9me2 peaks formed in $\mathrm{CD} 34^{+}$cells spread to surrounding regions in chromatin. As shown in Figure 1A, H3K9me2 marks appear to be nucleated at CGIs and then spread through genic regions in between. Spreading is suggested by the fact that the differentiated populations 
A

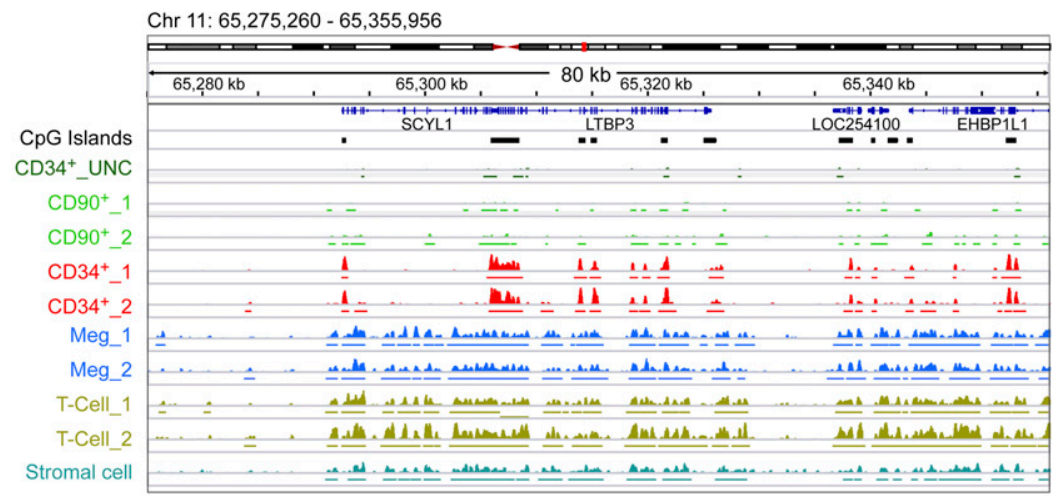

B

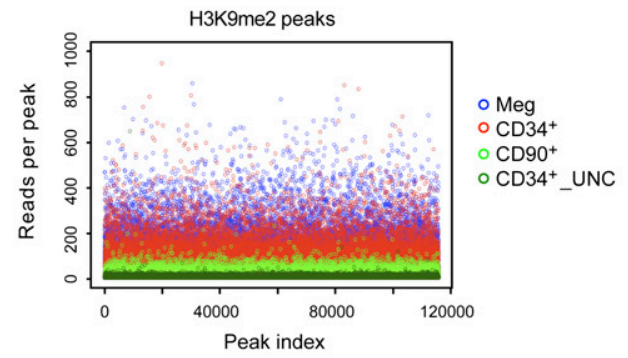

C

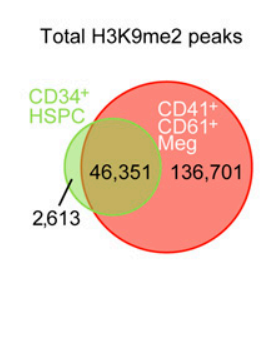

D

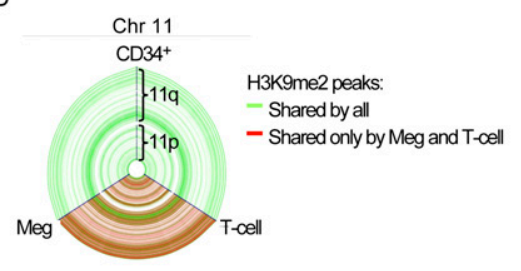

E

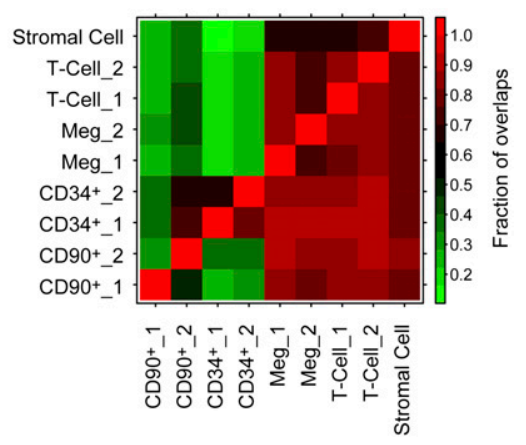

Figure 1. ChIP-seq analysis of $\mathrm{H} 3 \mathrm{~K} 9 \mathrm{me} 2$ patterning during HSPC lineage commitment. ChIP-seq was performed on cells from two independent donors with antibody against $\mathrm{H} 3 \mathrm{~K} 9 \mathrm{me} 2$ in progressive stages of the hematopoietic lineages or treated with UNC0638. $\mathrm{CD} 34^{+} \mathrm{CD} 90^{+} \mathrm{CD} 38^{\mathrm{lo}} \mathrm{CD} 45 \mathrm{RA}^{-}$ HSCs (denoted here as "CD90 $0^{+\prime}$ ) and CD41 $1^{+}$ $\mathrm{CD}^{+} 1^{+}$Megs were sorted from the same donors as the CD $34^{+}$HSPCs on day 4 and day 10 of primary cell cultures, respectively. $\mathrm{CD}^{+} \mathrm{T}$ cells were sorted from the blood of two different donors. "CD34+_UNC" indicates HPSCs treated with $2 \mu \mathrm{M}$ UNC0638 for 48 h. (A) Representative tracks from the Integrated Genome Viewer. The $Y$-axis indicates the number of reads (from 0 to 50 ) detected in 50-base-pair (bp) windows. "_1" and "_2" indicate biological replicates. (B) The number of reads for each peak, limited by the sample with the fewest called peaks. $(C)$ Venn diagram showing peak overlap between $\mathrm{CD} 34^{+}$HSPCs and $\mathrm{CD} 41^{+} \mathrm{CD} 61^{+}$Megs. Overlapping peaks share $>100$ bp. $(D)$ Hive plot representing chromosome 11 . The peaks are displayed with accurate genomic distances as blue nodes along the length of the axes, while peak overlaps are displayed as connected lines. Green lines represent peaks shared between CD $34^{+}$HSPCs, Megs, and T cells. Red lines represent peaks shared only between Megs and T cells. Unshared peaks by the three populations would appear as purple lines. (E) Heat map representing the fraction of overlaps between different samples. Overlaps are defined as read density peaks sharing at least $100 \mathrm{bp}$. The number of peaks overlapping is divided by the total number of peaks in that sample and displayed as a value between 0 and 1 . Comparisons are made with the samples in the rows. are derived from CD $34^{+}$HSPCs. In fact, for this experiment, the Meg population was derived during in vitro differentiation directly from the CD $34^{+}$HSPCs used for ChIP-seq. Moreover, these patterns were not due to in vitro differentiation artifacts, since uncultured T cells (from two different donors) gave the same highly reproducible pattern as the Megs. Thus, the results indicate that $\mathrm{H} 3 \mathrm{~K} 9 \mathrm{me} 2$ marks nucleated in $\mathrm{CD} 34^{+}$ cells spread to surrounding regions to form larger territories.

\section{H3K9me2 nucleation sites in HSPCs are enriched at H3K4me3 sites and CGIs}

We next examined H3K9me2 HSPC peak overlap with nine epigenetic marks and other genetic landmarks in HSPCs and differentiated cells. For epigenetic marks, we used the data from the work of Cui et al. (2009), who examined multiple histone marks in $\mathrm{CD}_{133^{+}}$human
HSPCs and also differentiated CD36 ${ }^{+}$erythrocytes (Fig. 2A; Supplemental Fig. S3A). The most frequent overlap occurred with H3K4me3. This mark is found at transcription start sites (TSSs) and is associated with active transcription when present with histone H3K36me3, which is found in gene bodies (Kolasinska-Zwierz et al. 2009), or epigenetic bivalency when found in combination with repressive marks (Attema et al. 2007; Gaspar-Maia et al. 2011). Interestingly, almost 50\% of the $\mathrm{H} 3 \mathrm{~K} 4 \mathrm{me} 3$ peaks in either $\mathrm{CD} 133^{+}$or $\mathrm{CD}_{3} 6^{+}$cells overlapped $\mathrm{H} 3 \mathrm{~K} 9 \mathrm{me} 2$ peaks in $\mathrm{CD} 34^{+}$HSPCs. This result is also consistent with $\mathrm{H} 3 \mathrm{~K} 9 \mathrm{me} 2$ being enriched at TSSs (Fig. 2B,C) and may suggest roles for G9a/GLP in facilitating chromatin structure and bivalency at promoters primed for expression in HSPCs.

Another interesting overlap was H4K20me1 ( 21\% of peaks in $\mathrm{CD}^{2} 6^{+}$cells) (Supplemental Fig. S3A). In contrast to $\mathrm{H} 3 \mathrm{~K} 4 \mathrm{me} 3$, this mark is found away from TSSs and has been implicated in regulating DNA damage responses, 
Chen et al.

A

\begin{tabular}{|c|cccc|}
\hline \multirow{4}{*}{$\begin{array}{c}\text { Histone } \\
\text { modifications }\end{array}$} & Intergenic Intragenic & TSS & $\begin{array}{c}\text { Overlap with } \\
\text { H3K9me2 }\end{array}$ \\
\cline { 2 - 5 } H2-AZ & $64 \%$ & $17 \%$ & $19 \%$ & $14 \%$ \\
\hline H4K20me1 & $50 \%$ & $42 \%$ & $8 \%$ & $13 \%$ \\
\hline H3K36me3 & $66 \%$ & $33 \%$ & $1 \%$ & $2 \%$ \\
\hline H3K27me1 & $63 \%$ & $34 \%$ & $3 \%$ & $5 \%$ \\
\hline H3K27me3 & $71 \%$ & $20 \%$ & $9 \%$ & $13 \%$ \\
\hline H3K9me1 & $59 \%$ & $38 \%$ & $3 \%$ & $7 \%$ \\
\hline H3K9me3 & $80 \%$ & $18 \%$ & $2 \%$ & $3 \%$ \\
\hline H3K4me1 & $61 \%$ & $33 \%$ & $6 \%$ & $8 \%$ \\
\hline H3K4me3 & $21 \%$ & $16 \%$ & $63 \%$ & $50 \%$ \\
\hline
\end{tabular}

C

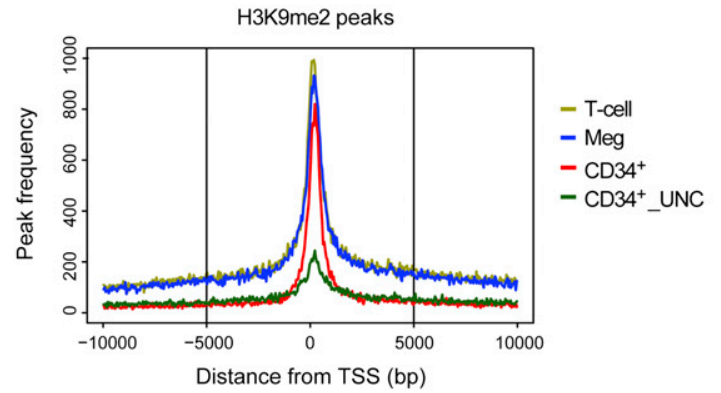

B

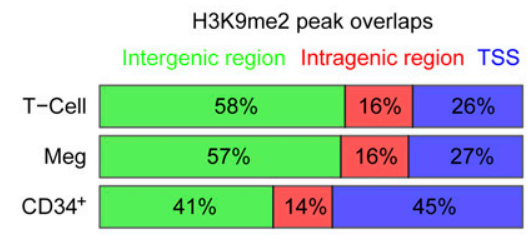

D

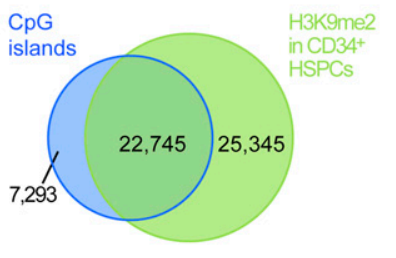

Figure 2. Overlaps between $\mathrm{H} 3 \mathrm{~K} 9 \mathrm{me} 2$ and other epigenetic marks and genetic landmarks. $(A)$ Overlap between $\mathrm{H} 3 \mathrm{~K} 9 \mathrm{me} 2$ peaks in CD34 ${ }^{+}$HSPCs and nine other histone marks in CD133 ${ }^{+}$HSPCs using data from the work of Cui et al. (2009). (B) Percentage of H3K9me2 peak associations with gene bodies and TSSs. CD34 ${ }^{+}$cells show enrichment at the TSS and deficiency in intergenic regions. (C) H3K9me2 peak frequency relative to TSSs of genes. (D) Overlap between H3K9me2 peaks and University of California at Santa Cruz (UCSC) CGIs in CD34 ${ }^{+}$HSPCs.

mitotic condensation, and also gene expression (Beck et al. 2012).

However, the most striking overlap was with CGIs (Fig. 2D; Supplemental Fig. S3B), which are DNA regions of high CpG density and are less likely to be methylated (Gardiner-Garden and Frommer 1987; Hodges et al. 2011). CGIs are generally near the gene promoters and are associated with regulation of gene expression (Saxonov et al. 2006). There are 28,691 predicted CGIs in the human genome (Cocozza et al. 2011). Of these, 79\% are associated with an $\mathrm{H} 3 \mathrm{~K} 9 \mathrm{me} 2$ peak in CD34 ${ }^{+}$HSPCs (Fig. 2D), which represents $47 \%$ of total H3K9me2. This result strongly suggests that nucleation of $\mathrm{H} 3 \mathrm{~K} 9 \mathrm{me} 2$ peaks is coordinated with CGIs in CD $34^{+}$HSPCs.

Taken together, these results demonstrate that $\mathrm{H} 3 \mathrm{~K} 9 \mathrm{me} 2$ patterning is progressive during HSPC lineage specification, H3K9me2 nucleation frequently occurs at CGIs in HSPCs, patterning events are dependent on G9a/GLP methyltransferase activity, and UNC0638 treatment alters $\mathrm{H} 3 \mathrm{~K} 9 \mathrm{me} 2$ patterning to better resemble those observed in primitive HSCs.

G9a/GLP-H3K9me2 patterning is not required for
maintenance of global DNA methylation in HSPCs

The strong overlap of $\mathrm{H} 3 \mathrm{~K} 9 \mathrm{me} 2$ nucleation sites in $\mathrm{CD}_{3} 4^{+}$cells with CGIs suggested the possibility that H3K9me2 patterning may be coordinated with DNA methylation. For example, G9a is shown to directly bind to maintenance DNA methyltransferase DNMT1 during
S phase in Cos-7 cells (Estève et al. 2006), and G9adeficient mouse ESCs display DNA hypomethylation (Ikegami et al. 2007). Therefore, we performed DNA methylation array analysis probing $99 \%$ of RefSeq genes and $96 \%$ of CGIs in $\mathrm{CD}^{+} 4^{+}$cells with or without UNC0638 treatment (Supplemental Fig. S4). However, UNC0638 treatment did not lead to global changes in DNA methylation. In fact, only $\sim 0.02 \%$ of methylation probes showed more than twofold difference compared with the DMSO control. These results suggest that inhibition of G9a/GLP activity and H3K9me2 patterning does not grossly perturb DNA methylation patterns in HSPCs, consistent with previous observations in human cancer cell lines (Vedadi et al. 2011).

\section{Nuclear staining of H3K9me2 confirms progressive patterning in committed HSPCS}

To confirm that $\mathrm{H} 3 \mathrm{~K} 9 \mathrm{me} 2$ patterning is progressive during HSPC lineage commitment, we next performed immunofluorescence (IF) staining of H3K9me2 marks in primitive and committed HSPCs. This analysis revealed that sorted $\mathrm{CD} 34^{+} \mathrm{CD} 90^{+} \mathrm{CD} 38{ }^{\text {lo }} \mathrm{CD} 45 \mathrm{RA}^{-}$HSCs showed significantly less nuclear staining than the total $\mathrm{CD} 34^{+}$ population (Fig. 3A,B). Cells stained with secondary antibody only were used as a negative control (Fig. 3C). Moreover, H3K9me2 staining in total $\mathrm{CD} 34^{+}$cells revealed the emergence of nuclear speckles or foci. As noted above, UNC0638 treatment revealed that increases in $\mathrm{H} 3 \mathrm{~K} 9 \mathrm{me} 2$ staining and nuclear speckling arose as a result 
A

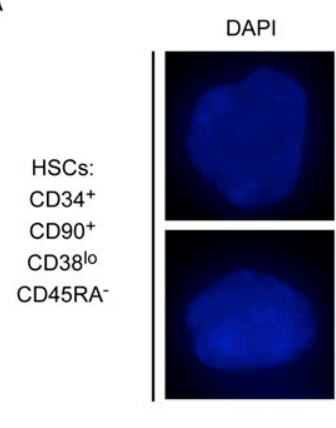

\begin{tabular}{c|} 
Unfractionated \\
CD34 \\
Control
\end{tabular}
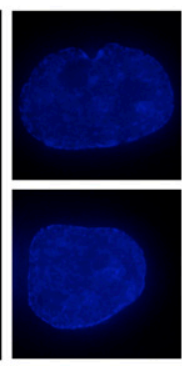
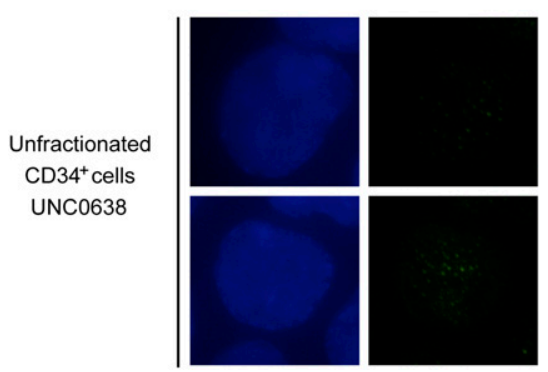

H3K9me2
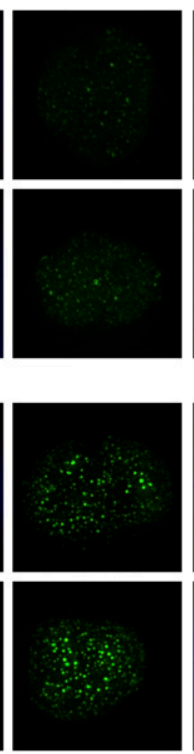

Merge
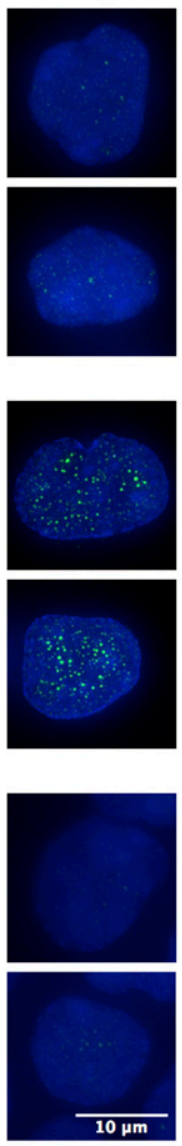

B

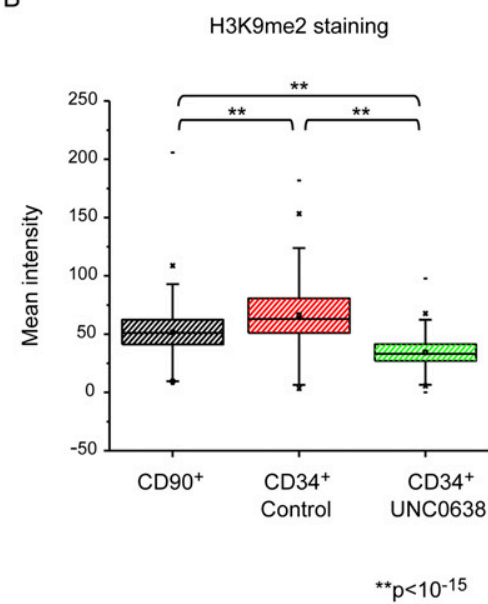

C

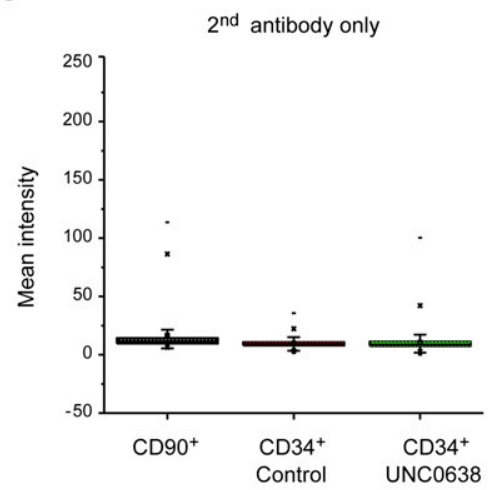

Figure 3. Nuclear staining of $\mathrm{H} 3 \mathrm{~K} 9 \mathrm{me} 2$. (A) Deconvoluted Z-section pictures of $\mathrm{H} 3 \mathrm{~K} 9 \mathrm{me} 2$ staining (green) in $\mathrm{CD} 34^{+} \mathrm{CD} 90^{+} \mathrm{CD} 38^{\mathrm{lo}} \mathrm{CD} 45 \mathrm{RA}{ }^{-}$ HSCs (top panels), unfractionated CD34 ${ }^{+}$cells (middle panels), and UNC0638-treated CD34 $4^{+}$cells (bottom panels). Nuclei were counterstained DAPI. $(B, C)$ Mean intensity of H3K9me2 staining $(B)$ or a secondary antibody-only staining $(C) ; n>380 ;\left({ }^{\star \star}\right) P<10^{-15}$.

of G9a/GLP activity (Fig. 3A). The quantification of staining did not examine foci per se but the entire nuclear staining intensity (Fig. 3B); the difference in foci formation is likely to be more dramatic than total nuclear staining. The formation of $\mathrm{H} 3 \mathrm{~K} 9 \mathrm{me} 2$ foci in committed HSPCs is consistent with progressive H3K9me2 patterning and development of H3K9me2-dependent higherorder chromatin changes during lineage specification. Nuclear staining of H3K9me2 in sorted stem and progenitor cells during early commitment steps of HSC differentiation also confirmed its progressive patterning (Supplemental Fig. S5C,D).

Inhibition of G9a/GLP in HSPCs results in promiscuous transcription of lineage-specific genes and affects transcriptional regulation of certain gene clusters

To evaluate the effect of G9a/GLP-dependent H3K9me2 on regulation of gene expression, we performed microarray gene expression analysis on unfractionated CD34 ${ }^{+}$ cells with or without treatment with UNC0638 (Fig. 4; Supplemental Fig. S6). Only 158 genes showed significant alterations in expression (Supplemental Table S1). Interestingly, among the 103 genes up-regulated by UNC0638 were those normally expressed in more mature hematopoietic cells as well as other tissues, including lung, liver, and brain, as assessed using the UniProt tissue database (Fig. 4A; Supplemental Table S2) and the Novartis normal tissue compendium (Fig. 4B). Portions of these results were confirmed by RT-qPCR analysis (Supplemental Fig. S6A).

Among the genes most significantly up-regulated by UNC0638 were the embryonic and fetal hemoglobin genes $H B E 1, H B G 1$, and $H B G 2$ (Fig. 4C; Supplemental Fig. S6A; Bauer and Orkin 2011). These genes are found in a cluster of embryonic, fetal, and adult hemoglobin genes on Chr11p15.5, which are progressively activated and repressed during development by a DNA element upstream of the cluster called the locus control region (LCR) (Chaturvedi et al. 2009). Consistent with our results, G9a/GLP-H3K9me2 has been shown to facilitate silencing of $H B E 1, H B G 1$, and $H B G 2$ during mammalian development by altering the chromatin secondary structure of LCR and the fetal hemoglobin genes (Chaturvedi et al. 2009). 
Chen et al.

A

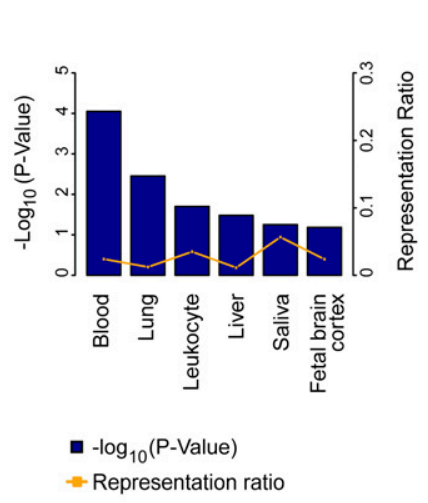

C

Chr 11: 5,246,696 - 5,291,373

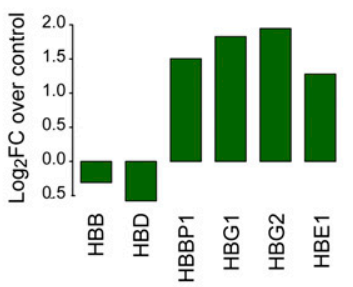

B

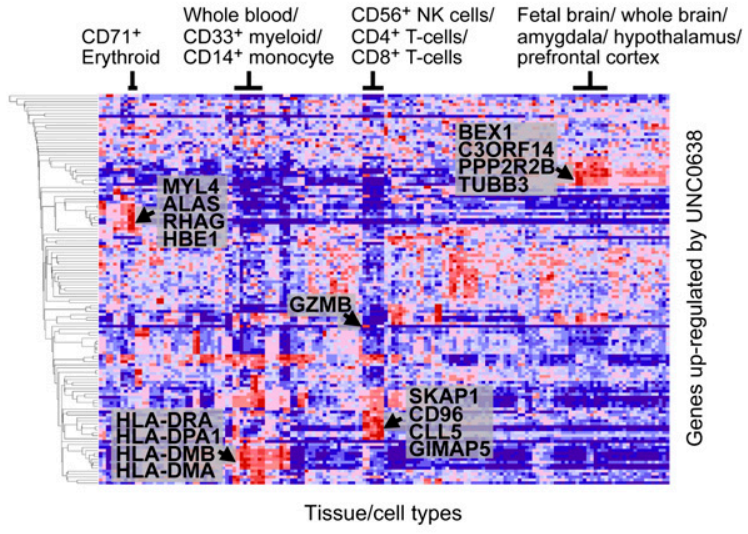

D

Chr 19: 57862645 - 58874214

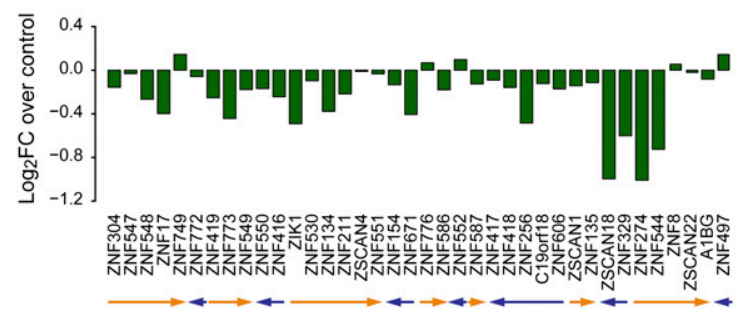

Figure 4. Inhibition of $\mathrm{H} 3 \mathrm{~K} 9 \mathrm{me} 2$ patterning in HSPCs results in up-regulation of multilineage gene expressions and affects transcriptional regulation of certain gene clusters. $(A)$ Tissue classifications of genes that were significantly changed in expression by UNC0638 with the UniProt tissue database. See also Supplemental Table S2. (B) Gene expression profiling performed using the Broad Institute's Molecular Signatures database. Genes that were considered differentially expressed were compared with the Novartis normal tissue compendium. Multilineage genes up-regulated by UNC0638 are shown. $(C, D)$ Clusters of genes that were significantly changed in expression by UNC0638. Looking for genes in close proximity in the differential expression set identified these clusters. The fold change represents the gene expression change between CD34 ${ }^{+}$HSPCs treated with UNC0638 compared with the DMSO control. Arrows indicate transcription directions.

In addition, we found evidence for G9a/GLP-dependent regulation of other gene clusters, including Chr6p21 (HLA-DRA/HLA-DPA1), ChrXq22 (BEX1/BEX2), Chr17q11 (CCL5/CCL23), and Chr19q13 (ZNF329/ZNF544) (Fig. 4D; Supplemental Fig. S6B-D). For the latter zinc finger $(Z N F)$ cluster, UNC0638 treatment resulted in repression of gene expression rather than derepression (Fig. 4D), suggesting that G9a/GLP activity is required for the maintenance of their expression in HSPCs. Previous studies have found a protein motif called the Kruppel-associated box (KRAB) domain in the majority of ZNF genes on chromosome 19, which is critical for protein-protein interaction (Eichler et al. 1998). KRAB-ZNF genes are largely involved in transcriptional repression (Eichler et al. 1998).

These results suggest, first, that inhibition of G9a/GLP by UNC0638 results in promiscuous transcription of hematopoiesis-affiliated and nonhematopoiesis-affiliated genes in HSPCs and, second, that G9a/GLP affects local structure of chromatin at specific gene clusters in HSPCs. Primitive HSCs have been hypothesized to have a more "open" chromatin structure that promotes promiscuous transcription of both nonhematopoietic and hematopoietic differentiation genes (Hu et al. 1997; Miyamoto et al. 2002; Månsson et al. 2007). Our data indicate that G9a/
GLP and H3K9me2 patterning may help restrict transcriptional promiscuity during HSPC differentiation. Thus, one intriguing implication is that $\mathrm{H} 3 \mathrm{~K} 9 \mathrm{me} 2 \mathrm{helps}$ facilitate adoption of alternate chromatin structures required for lineage commitment and specification. If true, inhibition of G9a/GLP and H3K9me2 patterning may block or delay lineage commitment.

Inhibition of $\mathrm{H} 3 \mathrm{~K} 9 \mathrm{me} 2$ patterning promotes primitive cell phenotypes and expansion of $C D 34^{+}$cells, which is further enhanced by SR1

To examine the possibility that G9a/GLP inhibition may delay or block adoption of HSPC cell fates, we performed a series of UNC0638 treatments on ex vivo cultures of CD34 ${ }^{+}$HSPCs followed by flow analysis of CD34 and lineage cell surface markers (Fig. 5; Supplemental Fig. S7). During a 2-wk time course, we observed that UNC0638 treatment increased the proportion of CD34 ${ }^{+}$cells $(23.6 \%$ in UNC0638-treated vs. $9.2 \%$ in the cytokines alone) while diminishing differentiated $\mathrm{CD} 15^{+}$cells (Fig. 5A). UNC0638 treatment also led to increases in the number of total nucleated cells and $\mathrm{CD}_{3} 4^{+}$cells, with $1 \mu \mathrm{M}$ UNC0638 having the best expansion effect (Fig. 5B). 
A
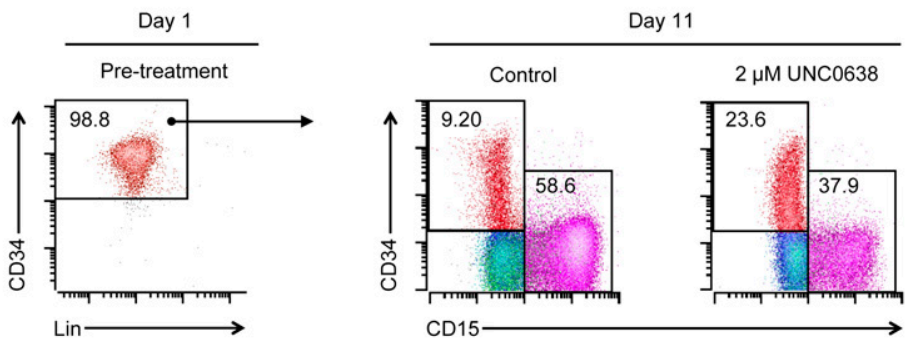

B
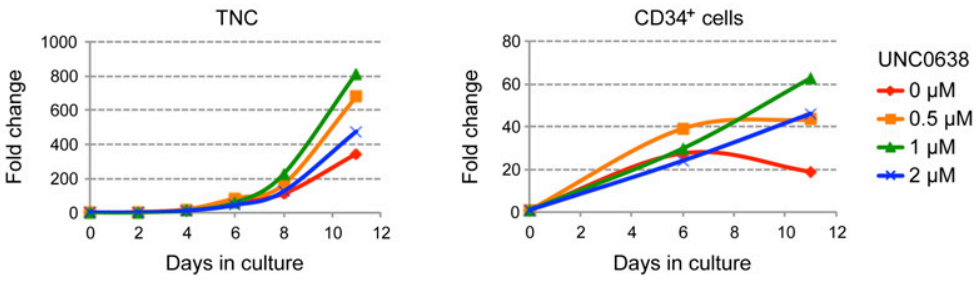

Figure 5. Inhibition of $\mathrm{H} 3 \mathrm{~K} 9 \mathrm{me} 2$ patterning promotes primitive cell phenotypes and expansion of CD $34^{+}$cells. $(A)$ Flow analysis of day 1 versus day 11 bone marrow (BM) CD $34^{+} \mathrm{CD} 38^{\text {lo }}$ cells. $\mathrm{CD} 34^{+} \mathrm{CD} 38^{\text {lo }}$ cells were cultured with or without UNC0638 for $11 \mathrm{~d}$. Multicolor flow analysis was performed on CD34 (HSPC marker) and CD15 (differentiated granulocyte marker). Lineage markers include CD3 ( $\mathrm{T}$ cell), CD11b (monocyte/granulocyte), CD14 (monocyte), CD15, CD19 (B cell), CD56 (natural killer cell), and CD235a (erythrocyte) (Baum et al. 1992; Manz et al. 2002). The colors shown are red $(\mathrm{CD} 34)^{+}$, magenta $\left(\mathrm{CD} 15^{+}\right)$, blue (HLA-DR $\left.{ }^{\mathrm{hi}}\right)$, cyan $\left(\right.$ HLA-DR $\left.{ }^{\text {lo }}\right)$, and green $\left(\mathrm{CD} 13^{\text {hi }}\right)$. Data are representative of multiple independent experiments using G-CSF-mobilized peripheral blood mononuclear cells (PBMC) or bone marrow-derived $\mathrm{CD} 34^{+}$cells. (B) UNC0638 from $0.5 \mu \mathrm{M}$ to $2 \mu \mathrm{M}$ increased the number of both total nucleated cells (TNCs) and $\mathrm{CD} 34^{+}$cells, with $1 \mu \mathrm{M}$ having the greatest expansion effect on $\mathrm{CD} 34^{+}$cells.
Moreover, UNC0638-treated HSCs also better retained CD49f, a marker associated with long-term repopulating HSCs (Supplemental Fig. S7B; Notta et al. 2011). These experiments were repeated multiple times with $\mathrm{CD} 34^{+}$ cells derived from bone marrow of normal donors or peripheral blood of G-CSF-mobilized donors with similar effects. Molecular studies revealed that G9 $a$ and GLP had similar expression in $\mathrm{CD} 34^{+}$primitive cells and CD $34^{-}$ differentiated cells (Supplemental Fig. S9A) and that UNC0638 treatment led to global loss of H3K9me2 (about twofold to fourfold) in HSPCs and a lesser decrease in H3K9me1 ( 1.4-fold) without affecting H3K9me3 levels or the expression of G9a, consistent with direct inhibition of its catalytic activity (Supplemental Fig. S9).

To further evaluate the effect of UNC0638 in promoting primitive HSPCs, we compared and combined it with treatments of SR1, a small molecule inhibitor of AHR, which was recently shown to promote expansion of human HSPCs in ex vivo cultures (Boitano et al. 2010). Flow analysis revealed that single treatments with UNC0638 or SR1 enhanced the proportion of more primitive HSPCs (Fig. 6A) - indicated by CD34 ${ }^{+}, \mathrm{CD}_{3} 8^{\text {lo }}$, $\mathrm{CD}^{+}$, and CD45RA ${ }^{-}$(Manz et al. 2002; Majeti et al. 2007) - compared with the no-drug control on day 14. SR1 treatments reproduced previously published results. Remarkably, cotreatment with SR1 and UNC0638 approximately doubled the effect of either drug alone for retention of $\mathrm{CD} 34^{+} \mathrm{CD} 38^{\text {lo }}$ and $\mathrm{CD} 34^{+} \mathrm{CD} 90^{+}$cells, resulting in $\mathrm{CD} 34^{+}$retention as high as $84 \%$ after $14 \mathrm{~d}$ of culture, compared with only $12 \%$ in untreated controls. Similar results were obtained from $\mathrm{CD}_{3}{ }^{+}$cells from G-CSFmobilized and bone marrow cells from multiple donors (Fig. 6A; Supplemental Fig. S10A).

To determine the cause of increase in $\mathrm{CD} 34^{+}$cells, we performed cumulative cell counts and viability assays for the total nucleated cells produced by HSPC cultures for 21 or $31 \mathrm{~d}$ as well as total $\mathrm{CD} 34^{+}$cells produced during the same time period. The results demonstrated that the increase in proportion of $\mathrm{CD} 34^{+}$cells was due to increased expansion of $\mathrm{CD}^{+} 4^{+}$cells. Notably, double treatment increased G-CSF-mobilized CD $34^{+}$expansion $>120$-fold by day 17 and increased bone marrow CD34 ${ }^{+}$ cells nearly 400 -fold by day 31 , while individual treatments and mock controls were considerably less potent (Fig. 6C; Supplemental Fig. S10C). Importantly, the livedead cell ratio did not change significantly between mock and treatments (Supplemental Fig. S12A), demonstrating that the increased cell counts were not due to increase in cell survival. Moreover, carboxyfluorescein succinimidyl ester (CFSE) dye retention assays revealed that by day 7 , all cells in culture had undergone at least four cell divisions, including CD34 ${ }^{+}$cells (Supplemental Fig. S12B). Thus, SR1/UNC0638 treatments did not result in maintenance of large numbers of quiescent cells. However, treated cultures did exhibit better dye retention, suggestive of expansion of slower-dividing primitive cells (Cheng et al. 2000; Zhang et al. 2006).

Similar results were obtained using different medium formulations, with or without serum and altered cytokine conditions (e.g., using EPO instead of TPO or EPO plus TPO) (Supplemental Fig. S13A,B; Birkmann et al. 1997), albeit overall CD34 ${ }^{+}$retention varied by treatment. Moreover, another substrate-competitive inhibitor of G9a/GLP, BIX01294 (Kubicek et al. 2007), phenocopied UNC0638 treatments for CD34 ${ }^{+}$retention (Supplemental Fig. S13C), while the use of an N-methyl analog of UNC0638, UNC0737, which is highly similar in structural but $>300$-fold less potent against G9a/GLP than UNC0638 (Vedadi et al. 2011), had no effect on HSPC expansion (data not shown). Both results further suggest that UNC0638 inhibition is specific to G9a/GLP activity.

SR1 and UNC0638 have divergent effects on HSPC expansion and gene expression

Given the observed differences in HSPC responses to SR1 and UNC0638 single treatments, we further investigated 
A

Day 1

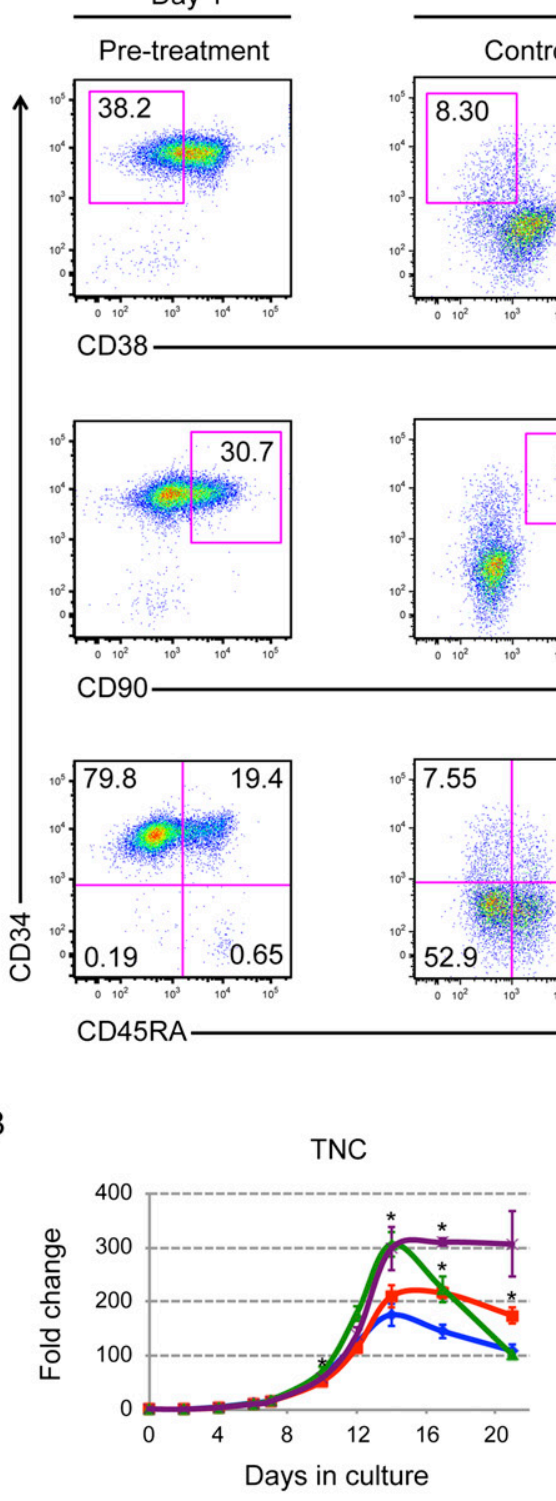

D

SCID-repopulating cells in day-14 expanded HSPCs

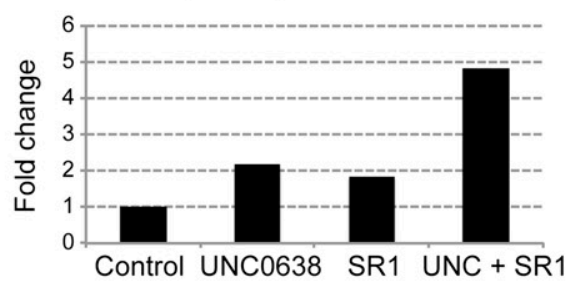

Day 14
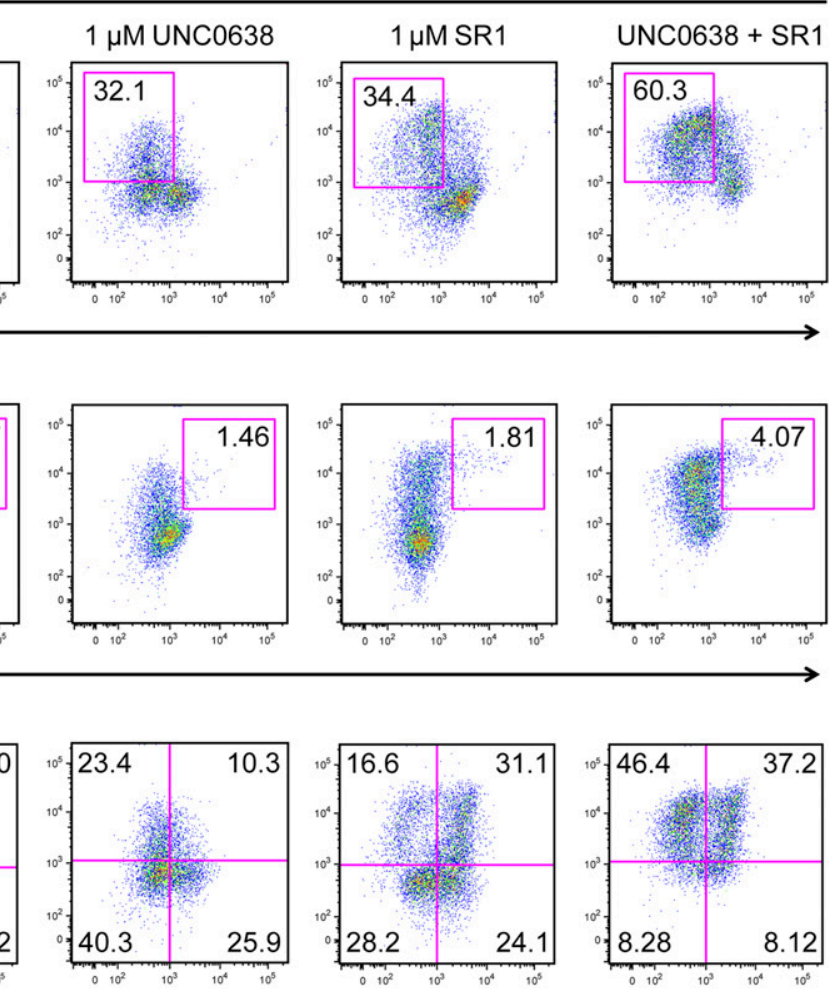

C

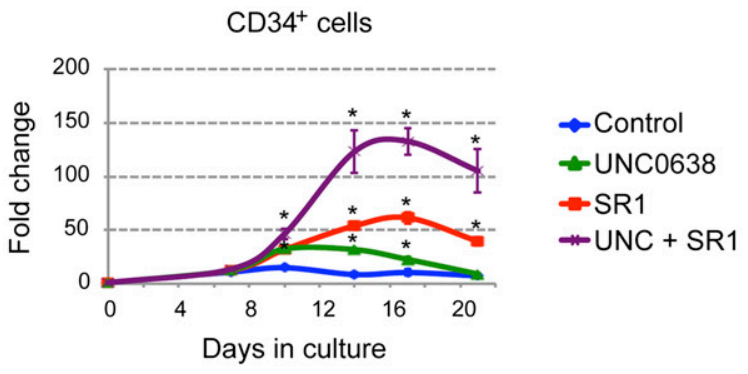

E

Canine transplantation of day-14 UNC0638/SR1-expanded CD34+ cells

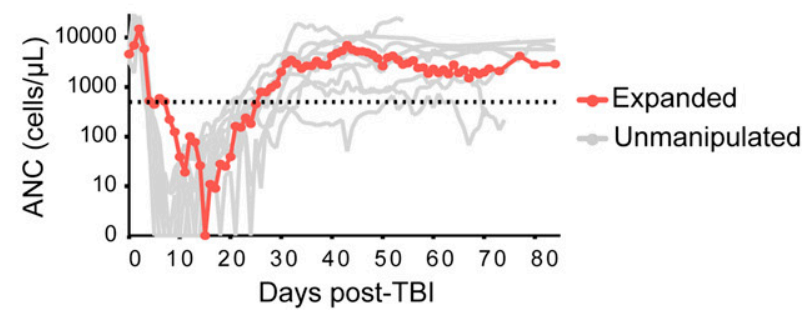

Figure 6. UNC0638 and SR1 additively enhanced retention of primitive HSPCs. (A) Flow analysis of CD34 ${ }^{+}$PBMCs on day 1 (pretreatment) or day 14 cultured with control (0.01\% DMSO), UNC0638, SR1, or UNC0638/SR1 dual treatment. Primitive HSPCs are detected by $\mathrm{CD} 34^{+} \mathrm{CD} 38^{\text {lo }}$ (top panels), CD $34^{+} \mathrm{CD} 90^{+}$(middle panels), and CD34 ${ }^{+} \mathrm{CD} 45 \mathrm{RA}^{-}$(bottom panels). See also Supplemental Figure S10 for flow analysis of bone marrow CD34 ${ }^{+}$cells. $(B, C)$ Fold expansion of total nucleated cells $(\mathrm{TNCs})(B)$ and CD34 ${ }^{+}$cells $(C)$ from control (blue diamonds), UNC0638-treated (green triangles), SR1-treated (red squares), or UNC0638 plus SR1-treated (purple crosses) conditions $(n=3)$. $\left(^{\star}\right)$ Student's $t$-test, $P<0.01$. (D) Engraftments of human day 14 expanded HSPCs in immunodeficient mice. The frequency of SCID-repopulating cells (SRCs) was calculated by Poisson statistics $(n=5)$. The number of SRCs in each group was calculated by multiplying its frequency by the total cell number at day 14. (E) Engraftment kinetics of absolute ANC in dog H501 that received 9.2 Gy of TBI and $1.7 \times 10^{7}$ expanded autologous CD34 ${ }^{+}$cells per kilogram, which were cultured for $14 \mathrm{~d}$ in UNC0638 and SR1 (red line). As a positive control (gray lines), shown is ANC recovery after major histocompatibility complex-matched littermate or unrelated cord blood progenitor cell transplantation with unmanipulated cells in 13 dogs after 9.2 Gy of TBI infused with cell doses comparable with H501. Dotted line indicates ANC $=500$ cells per microliter. 
the mechanism of SR1- and UNC0638-dependent HSPC expansion on different HSPCs subpopulations. We began by analyzing CD45RA-positive and CD45RA-negative progenitor pools, since UNC0638 increased the proportion of CD $34^{+} \mathrm{CD} 45 \mathrm{RA}^{-}$cells, while SR1 increased the proportion of $\mathrm{CD} 34^{+} \mathrm{CD} 45 \mathrm{RA}^{+}$cells (Fig. 6A). To this end, we purified $\mathrm{CD} 34^{+} \mathrm{CD} 45 \mathrm{RA}^{-}$and $\mathrm{CD} 34^{+} \mathrm{CD} 45 \mathrm{RA}^{+}$populations from day 4 HSPC cultures, which had not previously been treated with SR1 or UNC0638, and performed expansion assays on the isolated cells (Supplemental Fig. S14A). The results revealed that UNC0638 had no effect on the $\mathrm{CD} 34^{+} \mathrm{CD} 45 \mathrm{RA}^{+}$subpopulation, while SR1 preferentially stimulates its expansion. In contrast, both drugs had similar effects on CD $34^{+} \mathrm{CD} 45 \mathrm{RA}^{-}$cells (about eightfold peak expansion), and combined treatment resulted in 13-fold peak expansion (Supplemental Fig. S14A).

To further refine this experiment, expansion assays were performed on five pools of myeloid progenitors available in the HSPC culture system: HSCs, MPPs, CMPs, MEPs, and GMPs (Supplemental Fig. S14B). Progenitor pools were isolated by FACS and then expanded with or without SR1 and UNC0638. In these assays, SR1/ UNC0638 cotreatment most dramatically affected the primitive HSCs (i.e., $\mathrm{CD} 34^{+} \mathrm{CD} 90^{+} \mathrm{CD} 38^{\text {lo }} \mathrm{CD} 45 \mathrm{RA}^{-}$) - the CD34 $4^{+}$cells expanded $\sim 50$-fold after $14 \mathrm{~d}$ in SR1/ UNC0638, compared with about sixfold expansion for untreated controls. Moreover, single treatments were less effective than cotreatment, except for the CD45RA ${ }^{+}$ GMP pool, where UNC0638 had no effect (Supplemental Fig. S14B).

We next examined SR1- and UNCC0638-dependent changes in HSPC gene expressions to help determine the degree of similarity in their molecular mechanisms of action. We performed gene expression analysis for singletreated and cotreated CD34 ${ }^{+}$HSPCs (Supplemental Tables S1, S3). The results revealed a degree of divergence for singly treated HSPCs by cluster and multidimensional scaling analysis (Supplemental Fig. S15A,B). In fact, there was little overlap between single treatments and few overall genes that showed significant changes (Supplemental Fig. S15C). These results suggest that UNC0638 and SR1 act through different mechanisms.

\section{UNC0638- and SR1-treated HSPCs better retain} the ability to engraft and repopulate in vivo in mice and dogs

These results suggest that both UNC0638 and SR1 treatments are capable of enhancing the ex vivo expansion of $\mathrm{CD}_{3} 4^{+}$populations, and combining the two compounds multiplies the effect of either one alone. To demonstrate the retention of stem cell activity in vivo, we performed engraftment and repopulation experiments using SR1 and UNC0638 expanded HSPCs in small and large animal models of HSC transplantation.

We first measured SCID-repopulating cells (SRCs) in expanded human HSPC cultures using limiting dilution assays (LDAs) in immune-compromised mice (Szilvassy et al. 1990). In these assays, day 14 expanded HSPCs in mock-, single-, or cotreated conditions were injected into sublethally irradiated NOD/Scid/IL-2 receptor- $\gamma$-null (NSG) mice $(n=5)$. Eight weeks post-injection, percentages of human $\mathrm{CD} 45^{+}$cells in mouse bone marrow were examined to determine SRC frequency. By this assay, single-drug treatments resulted in an approximately twofold increase in the number of SRCs over mock treatment, while cotreatment resulted in an approximately fivefold increase (Fig. 6D). Importantly, human $\mathrm{CD} 45^{+}$cells contained both myeloid $\left(\mathrm{CD} 33^{+}\right)$and lymphoid $\left(\mathrm{CD} 19^{+}\right)$cells, indicating that the expanded cells retained multilineage reconstitution potential in vivo (Supplemental Fig. S16). However, it should be noted that in control experiments in which freshly isolated G-mobilized $\mathrm{CD} 34^{+}$cells were injected into NSG mice, as few as 200,000 CD34 ${ }^{+}$cells displayed engraftment and multilineage differentiation in mice $(n=5)$, whereas no mouse was engrafted with 200,000 UNC0638/SR1 expanded day 14 CD34 $4^{+}$cells $(n=$ 5). This suggests that while SR $1 / \mathrm{UNC} 0638$ treatment does enhance retention of primitive stem cell markers and stem cell activity compared with the no-drug control expanded cells, the overall stem cell activity as measured in this surrogate assay still diminishes when compared with unexpanded cells.

We next examined the effects of SR1/UNC0638 treatment on HSC activity during expansion of canine CD $34^{+}$ cells, as previous studies conducted over four decades show that the outcomes of HSC transplantation in dogs accurately predict the outcomes in human patients (Ostrander and Giniger 1997; Thomas and Storb 1999). To this end, a recipient dog was given 9.2 Gy of total body irradiation (TBI), a myeloablative dose, and then infused with autologous day 14 SR1/UNC0638 expanded HSPCs, $1.7 \times 10^{7}$ total nucleated cells per kilogram. To evaluate reconstitution, absolute neutrophil counts (ANCs) were monitored daily until complete hematopoietic recovery for $84 \mathrm{~d}$ post-transplantation. Remarkably, transplantation of SR1/UNC0638 expanded cells led to full recovery of the recipient (Fig. 6E; Georges et al. 2010). These results are consistent with the notion that SR1/UNC0638 expansion at the very least sustains canine HSC activity during 14-d expansion of HSPCs. This is in contrast to an unpublished study $(n=4)$ in which canine CD34 ${ }^{+}$HSPCs cultured for 7-10 d in cytokines only failed to engraft in dogs conditioned with 9.2 Gy of TBI (M Mielcarek, pers. comm.).

These results strongly suggested that SR1/UNC0638 cotreatment allows retention of primitive HSCs during in vitro expansion. It holds promise for expanding HSPCs for transplantation purposes (Dahlberg et al. 2011).

\section{Discussion}

Here, we examined roles for G9a/GLP activity in normal human HSPCs using an in vitro culture and differentiation system and a newly developed chemical probe targeting G9a/GLP, UNC0638 (Vedadi et al. 2011). Our studies led to several unexpected findings. First, they revealed that G9a/GLP-dependent $\mathrm{H} 3 \mathrm{~K} 9 \mathrm{me} 2$ patterning is progressive during HSPC lineage commitment: $\mathrm{H} 3 \mathrm{~K} 9 \mathrm{me} 2$ 
marks are nucleated at $79 \%$ of CGIs in CD $34^{+}$HSPCs and then spread to surrounding regions during differentiation to form characteristic H3K9me2 territories in euchromatic regions of all chromosomes. Second, they suggested that G9a/GLP and H3K9me2 patterning may help restrict transcription of multilineage genes during HSPC differentiation. Third, they showed that UNC0638 treatment in G-CSF mobilized peripheral blood and bone marrow-derived $\mathrm{CD}_{34}{ }^{+}$HSPCs promotes retention of primitive HSCs in vitro and that this effect is enhanced by cotreatment with the AHR inhibitor SR1 (Boitano et al. 2010). Fourth, they demonstrated that UNC0638 and SR1 target primitive HSCs but through different mechanisms, as judged by differences in expansion effects on committed progenitors and gene expression profiles after treatments. Taken together, these results suggest that G9a/GLP-dependent H3K9me2 patterning plays key roles in early lineage commitment of adult HSPCs. However, these results also raise several questions regarding G9a/GLP function and $\mathrm{H} 3 \mathrm{~K} 9 \mathrm{me} 2$ marks in HSPCs.

Key among these is: What specific roles do $\mathrm{H} 3 \mathrm{~K} 9 \mathrm{me} 2$ marks play during HSPC lineage specification? During mammalian development, G9a/GLP activity gives rise to large organized chromatin K9me2 modification (LOCK) regions of up to $4.9 \mathrm{Mb}$ (Wen et al. 2009), which have been proposed to facilitate retention of higher-order chromatin structure and epigenetic memory. LOCKs show apparent tissue-specific patterns based on examination of H3K9me2 marks in the mouse brain and liver and human placenta (Wen et al. 2009). Our results are consistent with formation of LOCK-like H3K9me2 territories during human hematopoiesis and, moreover, support roles for H3K9me2 in the development of higher-order chromatin structures during HSPC lineage specification. G9a/GLP-dependent H3K9me2 marks arise in HSPC nuclei as "speckles," which likely indicates the formation of organized chromatin structures during lineage commitment. Furthermore, UNC0638 treatment affects expression of multiple genes appearing in chromosome gene clusters in HSPCs (e.g., $6 p 21,11 p 15$, and 17q11), suggesting that H3K9me2 facilitates formation of local chromosome structures at these loci. For example, G9a/GLP-H3K9me2 has been shown to facilitate silencing of $H B E 1, H B G 1$, and $H B G 2$ during mammalian development by altering the chromatin secondary structure of LCR and the fetal hemoglobin genes (Chaturvedi, et al. 2009). Expression of these genes is derepressed in UNC0638-treated HSPCs. Thus, the results are consistent with the notion that UNC0638 treatment partially blocks formation of higher-order chromatin structure in HSPCs.

Another question is how H3K9me2 marks arise in committed hematopoietic cells. Since G9a/GLP-dependent H3K9 methylation can occur de novo, pre-existing epigenetic marks are not required (Collins and Cheng 2010). Our results show that H3K9me2 nucleation sites in HSPCs most strongly overlap with CGIs, perhaps suggesting a functional link between H3K9me2 and DNA methylation. Since CGIs are generally hypomethylated in HSPCs (Hodges et al. 2011), one possibility is that
G9a/GLP and DNMT activity are coordinated such that H3K9me2 marks are laid down by default only where CpGs are unmethylated (i.e., in CGIs). Alternatively, specificity factors might target G9a/GLP to CGIs. For example, in ESCs, G9a/GLP bind to UHRF1, which in turn binds to hemimethylated CpG sites (Kim et al. 2009).

One intriguing implication of our results is that the absence of $\mathrm{H} 3 \mathrm{~K} 9 \mathrm{me} 2$ marks in HSCs may facilitate adoption of alternate chromatin and chromosomal structures required for lineage commitment and specification. This would be consistent with the concept that HSCs harbor an open chromatin structure that results in promiscuous transcription (Akashi et al. 2003), which is incompatible with the presence of $\mathrm{H} 3 \mathrm{~K} 9 \mathrm{me} 2$ chromatin territories.

This study also has important implications for clinical uses of human HSCs. One of the long-standing roadblocks limiting application of HSCs has been our inability to effectively expand and/or immortalize HSCs ex vivo (Dahlberg et al. 2011). Initial attempts at ex vivo expansion of HSPCs focused on cytokine stimulation to support survival and proliferation of lineage-committed progeny in the hope of expanding true HSCs as well (Sauvageau et al. 2004; Dahlberg et al. 2011). However, these attempts have largely failed to enhance in vivo engraftment in patients.

One notable exception is stimulation of Notch signaling in cord blood units (Ohishi et al. 2002; Delaney et al. 2010), which allows more rapid myeloid reconstitution in patients with post-transplantation cytopenias. However, it appears that Notch-expanded cord blood units may be depleted of long-term repopulating HSCs (Dahlberg et al. 2011) and, as a result, are given in combination with naive cord blood units to provide stem cells to improve longterm engraftment. Moreover, Notch-driven expansion only affects fetal cord blood stem cells but has no effect on adult human HSC expansion (Dahlberg et al. 2011).

However, Cooke and colleagues (Boitano et al. 2010) recently discovered that SR1, a small molecular inhibitor of the AHR, promotes expansion of CD $34^{+}$human HSPCs in ex vivo cultures. Our SR1 trials similarly support these findings in adult stem cells, although SR1 treatment did not dramatically affect expression of AHR pathway targets, as previously reported (Boitano et al. 2010).

Our studies with UNC0638 revealed that this drug on its own had effects similar to SR1 with respect to retention of $\mathrm{CD} 4^{+}$HSPCs and also HSPC engraftment activity in immunocompromised mice. Moreover, examination of SR1 and UNC0638 treatment revealed that each affects both common and distinct populations of HSPCs, with most dramatic effects observed on primitive HSCs. The mechanisms giving rise to their expansion effects were clearly divergent based on transcriptional profiling, and there was no evidence of cross regulation of AHR pathway and/or G9a/GLP gene expression.

We envision several clinical applications of SR1/ UNC0638 treatments. First is in the expansion of HSCs for transplantation. There are many cases in which transplantation products are critically limited (e.g., young 
or small donors, prior treatment of the donor, or failure to mobilize). Second is in accelerating transplantation recovery. Post-transplantation cytopenias, including neutropenias and thrombocytopenias, are commonplace and lead to life-threatening infections or bleeding and result in costly, extended hospitalization (Dahlberg et al. 2011). Our results from modeling transplantation of SR1/ UNC0638 cultures in a canine model suggest that combining day 14 expanded cultures with nonmanipulated HSPCs may help bridge post-transplantation neutropenia in addition to providing long-term engraftment. Third, it is conceivable that UNC0638 has a potential benefit to patients with $\beta$-hemoglobinopathies by reactivating the embryonic and fetal hemoglobin, whose activation is associated with milder symptoms (Akinsheye et al. 2011). Last, we envision that SR1 and UNC0638 may be combined with additional experimental manipulations to practically immortalize single HSCs for unlimited expansion while retaining developmental potential, similar to ESCs or induced pluripotent stem cells.

In conclusion, our data strongly suggest that G9a/GLPmediated $\mathrm{H} 3 \mathrm{~K} 9 \mathrm{me} 2$ patterning is required for HSPC lineage specification and that its inhibition leads to delayed differentiation and retention of the HSPCs. These findings should prove useful for clinical and experimental applications limited by current techniques to maintain HSPCs in vitro.

\section{Materials and methods}

\section{Cell culture}

Human CD34 ${ }^{+}$cells from G-CSF-mobilized peripheral blood or bone marrow of healthy adults were purchased from the Fred Hutchinson Cancer Research Center Cell Processing Shared Resource. Cells were maintained in either serum-containing medium (IMDM with $10 \%$ fetal calf serum, supplemented with $1 \times$ antibiotics; $100 \mathrm{ng} / \mathrm{mL}$ SCF, IL-6, Flt3L, TPO, G-CSF; $200 \mathrm{ng} / \mathrm{mL}$ IL-3) or the serum-free medium (SFEM; StemCell Technologies), supplemented with $1 \times$ antibiotics and $100 \mathrm{ng} / \mathrm{mL}$ SCF, IL-6, Flt3L, and TPO. UNC0638 (Sigma) and SR1 (AMRI) were resuspended in DMSO and used at the indicated concentrations. Cells were cultured at $37^{\circ} \mathrm{C}$ in $5 \% \mathrm{CO}_{2} / 95 \%$ air at a density between 0.5 million and 1.5 million cells per milliliter.

\section{ChIP-seq}

Cells were cross-linked with $1 \%$ formaldehyde and sonicated to achieve chromosome fragments of 200-400 bp. ChIPs were performed using antibodies directed against H3K9me2 (Abcam). Samples are prepared for Illumina-based sequencing using the Encore NGS Library System I (NuGEN). High-throughput sequencing by synthesis (HT-SBS) was performed on an Illumina HiSeq 2000 sequencer.

Additional methods and data analysis can be found in the Supplemental Material.

\section{Acknowledgments}

We thank Shelly Heimfeld, Irv Bernstein, Andrew Emili, Matthew Ferro, David Emery, Tony Blau, and members of the Paddison and Torok-Storb laboratories for helpful discussions. We thank Shelly Heimfeld for providing human HSPCs; Melissa
Comstock, LaKeisha Perkins, and Cynthia Nourigat for their help with xenograft studies; Robert Jordan for technical assistance with canine transplants; Alyssa Dawson and Andy Marty for technical assistance with microarray and next-generation sequencing; the Cincinnati Cell Characterization Core (C4) and its Molecular (Elke Grassman), Genomic (Mehdi Kedachhe), and Bioinformatics (Bruce Aronow and Philip Dexheimer) subcores for help with DNA methylation array and analysis; Julio Vazquez Lopez for technical assistance with the fluorescence microscope; Gretchen Johnson and Megan Wilson for help with flow analysis; and Pam Lindberg for assistance in manuscript preparation. This work was supported by FHCRC institutional funds (P.J.P); grants from the Pew scholar program (to P.J.P.), NIH/NHLBI (U01 HL099993 to B.T.S., P.J.P., and X.C), and NIDDK/NIH (P30 DK56465 to B.T.S. and P.J.P.); the P30DK056465 740 CCEH Pilot awards (to P.J.P. and X.C.); NHLBI U01-HL099997 Pilot award (to P.J.P. and X.C.); and the HHMI/UW Molecular Medicine Scholar award (to X.C.).

\section{References}

Akashi K, He X, Chen J, Iwasaki H, Niu C, Steenhard B, Zhang J, Haug J, Li L. 2003. Transcriptional accessibility for genes of multiple tissues and hematopoietic lineages is hierarchically controlled during early hematopoiesis. Blood 101: 383-389.

Akinsheye I, Alsultan A, Solovieff N, Ngo D, Baldwin CT, Sebastiani P, Chui DH, Steinberg MH. 2011. Fetal hemoglobin in sickle cell anemia. Blood 118: 19-27.

Attema JL, Papathanasiou P, Forsberg EC, Xu J, Smale ST, Weissman IL. 2007. Epigenetic characterization of hematopoietic stem cell differentiation using miniChIP and bisulfite sequencing analysis. Proc Natl Acad Sci 104: 12371-12376.

Bauer DE, Orkin SH. 2011. Update on fetal hemoglobin gene regulation in hemoglobinopathies. Curr Opin Pediatr 23: $1-8$.

Baum CM, Weissman IL, Tsukamoto AS, Buckle AM, Peault B. 1992. Isolation of a candidate human hematopoietic stemcell population. Proc Natl Acad Sci 89: 2804-2808.

Beck DB, Oda H, Shen SS, Reinberg D. 2012. PR-Set7 and H4K20me1: At the crossroads of genome integrity, cell cycle, chromosome condensation, and transcription. Genes Dev 26: 325-337.

Birkmann J, Oez S, Smetak M, Kaiser G, Kappauf H, Gallmeier WM. 1997. Effects of recombinant human thrombopoietin alone and in combination with erythropoietin and earlyacting cytokines on human mobilized purified CD34 ${ }^{+}$progenitor cells cultured in serum-depleted medium. Stem Cells 15: $18-32$.

Boitano AE, Wang J, Romeo R, Bouchez LC, Parker AE, Sutton SE, Walker JR, Flaveny CA, Perdew GH, Denison MS, et al. 2010. Aryl hydrocarbon receptor antagonists promote the expansion of human hematopoietic stem cells. Science 329: 1345-1348.

Chaturvedi CP, Hosey AM, Palii C, Perez-Iratxeta C, Nakatani Y, Ranish JA, Dilworth FJ, Brand M. 2009. Dual role for the methyltransferase G9a in the maintenance of $\beta$-globin gene transcription in adult erythroid cells. Proc Natl Acad Sci 106: 18303-18308.

Cheng T, Rodrigues N, Shen H, Yang Y, Dombkowski D, Sykes M, Scadden DT. 2000. Hematopoietic stem cell quiescence maintained by p21cip1/waf1. Science 287: 1804-1808.

Cocozza S, Akhtar MM, Miele G, Monticelli A. 2011. CpG islands undermethylation in human genomic regions under selective pressure. PLOS ONE 6: e23156. doi: 10.1371/journal. pone.0023156. 
Collins R, Cheng X. 2010. A case study in cross-talk: The histone lysine methyltransferases G9a and GLP. Nucleic Acids Res 38: 3503-3511.

Collins RE, Northrop JP, Horton JR, Lee DY, Zhang X, Stallcup MR, Cheng X. 2008. The ankyrin repeats of G9a and GLP histone methyltransferases are mono- and dimethyllysine binding modules. Nat Struct Mol Biol 15: 245-250.

Cui K, Zang C, Roh TY, Schones DE, Childs RW, Peng W, Zhao K. 2009. Chromatin signatures in multipotent human hematopoietic stem cells indicate the fate of bivalent genes during differentiation. Cell Stem Cell 4: 80-93.

Dahlberg A, Delaney C, Bernstein ID. 2011. Ex vivo expansion of human hematopoietic stem and progenitor cells. Blood 117: 6083-6090.

Delaney C, Heimfeld S, Brashem-Stein C, Voorhies H, Manger RL, Bernstein ID. 2010. Notch-mediated expansion of human cord blood progenitor cells capable of rapid myeloid reconstitution. Nat Med 16: 232-236.

Doulatov S, Notta F, Laurenti E, Dick JE. 2012. Hematopoiesis: A human perspective. Cell Stem Cell 10: 120-136.

Eichler EE, Hoffman SM, Adamson AA, Gordon LA, McCready P, Lamerdin JE, Mohrenweiser HW. 1998. Complex $\beta$-satellite repeat structures and the expansion of the zinc finger gene cluster in 19p12. Genome Res 8: 791-808.

Estève PO, Chin HG, Smallwood A, Feehery GR, Gangisetty O, Karpf AR, Carey MF, Pradhan S. 2006. Direct interaction between DNMT1 and G9a coordinates DNA and histone methylation during replication. Genes Dev 20: 3089-3103.

Feldman N, Gerson A, Fang J, Li E, Zhang Y, Shinkai Y, Cedar H, Bergman Y. 2006. G9a-mediated irreversible epigenetic inactivation of Oct-3/4 during early embryogenesis. Nat Cell Biol 8: 188-194.

Gardiner-Garden M, Frommer M. 1987. CpG islands in vertebrate genomes. J Mol Biol 196: 261-282.

Gaspar-Maia A, Alajem A, Meshorer E, Ramalho-Santos M. 2011. Open chromatin in pluripotency and reprogramming. Nat Rev Mol Cell Biol 12: 36-47.

Georges GE, Lesnikov V, Baran SW, Aragon A, Lesnikova M, Jordan R, Laura Yang YJ, Yunusov MY, Zellmer E, Heimfeld $S$, et al. 2010. A preclinical model of double- versus singleunit unrelated cord blood transplantation. Biol Blood Marrow Transplant 16: 1090-1098.

Graf L, Iwata M, Torok-Storb B. 2002. Gene expression profiling of the functionally distinct human bone marrow stromal cell lines HS-5 and HS-27a. Blood 100: 1509-1511.

Gyory I, Wu J, Fejér G, Seto E, Wright KL. 2004. PRDI-BF1 recruits the histone $\mathrm{H} 3$ methyltransferase G9a in transcriptional silencing. Nat Immunol 5: 299-308.

Hodges E, Molaro A, Dos Santos CO, Thekkat P, Song Q, Uren PJ, Park J, Butler J, Rafii S, McCombie WR, et al. 2011. Directional DNA methylation changes and complex intermediate states accompany lineage specificity in the adult hematopoietic compartment. Mol Cell 44: 17-28.

Hu M, Krause D, Greaves M, Sharkis S, Dexter M, Heyworth C, Enver T. 1997. Multilineage gene expression precedes commitment in the hemopoietic system. Genes Dev 11: 774785.

Ikegami K, Iwatani $M$, Suzuki $M$, Tachibana M, Shinkai Y, Tanaka S, Greally JM, Yagi S, Hattori N, Shiota K. 2007. Genome-wide and locus-specific DNA hypomethylation in G9a deficient mouse embryonic stem cells. Genes Cells 12: $1-11$.

Kim JK, Estève PO, Jacobsen SE, Pradhan S. 2009. UHRF1 binds G9a and participates in p21 transcriptional regulation in mammalian cells. Nucleic Acids Res 37: 493-505.
Kolasinska-Zwierz P, Down T, Latorre I, Liu T, Liu XS, Ahringer J. 2009. Differential chromatin marking of introns and expressed exons by H3K36me3. Nat Genet 41: 376-381.

Kubicek S, O'Sullivan RJ, August EM, Hickey ER, Zhang Q, Teodoro ML, Rea S, Mechtler K, Kowalski JA, Homon CA, et al. 2007. Reversal of $\mathrm{H} 3 \mathrm{~K} 9 \mathrm{me} 2$ by a small-molecule inhibitor for the G9a histone methyltransferase. Mol Cell 25: 473-481.

Litt MD, Simpson M, Gaszner M, Allis CD, Felsenfeld G. 2001. Correlation between histone lysine methylation and developmental changes at the chicken $\beta$-globin locus. Science 293: 2453-2455.

Majeti R, Park CY, Weissman IL. 2007. Identification of a hierarchy of multipotent hematopoietic progenitors in human cord blood. Cell Stem Cell 1: 635-645.

Månsson R, Hultquist A, Luc S, Yang L, Anderson K, Kharazi S, Al-Hashmi S, Liuba K, Thorén L, Adolfsson J, et al. 2007. Molecular evidence for hierarchical transcriptional lineage priming in fetal and adult stem cells and multipotent progenitors. Immunity 26: 407-419.

Manz MG, Miyamoto T, Akashi K, Weissman IL. 2002. Prospective isolation of human clonogenic common myeloid progenitors. Proc Natl Acad Sci 99: 11872-11877.

Miyamoto T, Iwasaki H, Reizis B, Ye M, Graf T, Weissman IL, Akashi K. 2002. Myeloid or lymphoid promiscuity as a critical step in hematopoietic lineage commitment. Dev Cell 3: 137-147.

Noma K, Allis CD, Grewal SI. 2001. Transitions in distinct histone H3 methylation patterns at the heterochromatin domain boundaries. Science 293: 1150-1155.

Notta F, Doulatov S, Laurenti E, Poeppl A, Jurisica I, Dick JE. 2011. Isolation of single human hematopoietic stem cells capable of long-term multilineage engraftment. Science 333: 218-221.

Novershtern N, Subramanian A, Lawton LN, Mak RH, Haining WN, McConkey ME, Habib N, Yosef N, Chang CY, Shay T, et al. 2011. Densely interconnected transcriptional circuits control cell states in human hematopoiesis. Cell 144: 296309.

O'Geen H, Echipare L, Farnham PJ. 2011. Using ChIP-seq technology to generate high-resolution profiles of histone modifications. Methods Mol Biol 791: 265-286.

Ohishi K, Varnum-Finney B, Bernstein ID. 2002. Delta-1 enhances marrow and thymus repopulating ability of human CD $34^{+} \mathrm{CD} 38^{-}$cord blood cells. J Clin Invest 110: $1165-$ 1174.

Orkin SH, Zon LI. 2008. Hematopoiesis: An evolving paradigm for stem cell biology. Cell 132: 631-644.

Ostrander EA, Giniger E. 1997. Semper fidelis: What man's best friend can teach us about human biology and disease. Am I Hum Genet 61: 475-480.

Peters AH, Kubicek S, Mechtler K, O'Sullivan RJ, Derijck AA, Perez-Burgos L, Kohlmaier A, Opravil S, Tachibana M, Shinkai Y, et al. 2003. Partitioning and plasticity of repressive histone methylation states in mammalian chromatin. Mol Cell 12: 1577-1589.

Rice JC, Briggs SD, Ueberheide B, Barber CM, Shabanowitz J, Hunt DF, Shinkai Y, Allis CD. 2003. Histone methyltransferases direct different degrees of methylation to define distinct chromatin domains. Mol Cell 12: 1591-1598.

Roopra A, Qazi R, Schoenike B, Daley TJ, Morrison JF. 2004. Localized domains of G9a-mediated histone methylation are required for silencing of neuronal genes. Mol Cell 14: 727-738.

Sauvageau G, Iscove NN, Humphries RK. 2004. In vitro and in vivo expansion of hematopoietic stem cells. Oncogene 23: 7223-7232. 
Saxonov S, Berg P, Brutlag DL. 2006. A genome-wide analysis of CpG dinucleotides in the human genome distinguishes two distinct classes of promoters. Proc Natl Acad Sci 103: 14121417.

Su RC, Brown KE, Saaber S, Fisher AG, Merkenschlager M, Smale ST. 2004. Dynamic assembly of silent chromatin during thymocyte maturation. Nat Genet 36: 502-506.

Szilvassy SJ, Humphries RK, Lansdorp PM, Eaves AC, Eaves CJ. 1990. Quantitative assay for totipotent reconstituting hematopoietic stem cells by a competitive repopulation strategy. Proc Natl Acad Sci 87: 8736-8740.

Tachibana M, Sugimoto K, Nozaki M, Ueda J, Ohta T, Ohki M, Fukuda M, Takeda N, Niida H, Kato H, et al. 2002. G9a histone methyltransferase plays a dominant role in euchromatic histone $\mathrm{H} 3$ lysine 9 methylation and is essential for early embryogenesis. Genes Dev 16: 1779-1791.

Thomas ED, Storb R. 1999. The development of the scientific foundation of hematopoietic cell transplantation based on animal and human studies. In Hematopoietic cell transplantation (ed. ED Thomas et al.), pp. 1-11. Blackwell Science, Malden, MA.

Vedadi M, Barsyte-Lovejoy D, Liu F, Rival-Gervier S, AllaliHassani A, Labrie V, Wigle TJ, Dimaggio PA, Wasney GA, Siarheyeva A, et al. 2011. A chemical probe selectively inhibits G9a and GLP methyltransferase activity in cells. Nat Chem Biol 7: 566-574.

Wen B, Wu H, Shinkai Y, Irizarry RA, Feinberg AP. 2009. Large histone H3 lysine 9 dimethylated chromatin blocks distinguish differentiated from embryonic stem cells. Nat Genet 41: 246-250.

Zhang J, Grindley JC, Yin T, Jayasinghe S, He XC, Ross JT, Haug JS, Rupp D, Porter-Westpfahl KS, Wiedemann LM, et al. 2006. PTEN maintains haematopoietic stem cells and acts in lineage choice and leukaemia prevention. Nature 441: 518522 . 


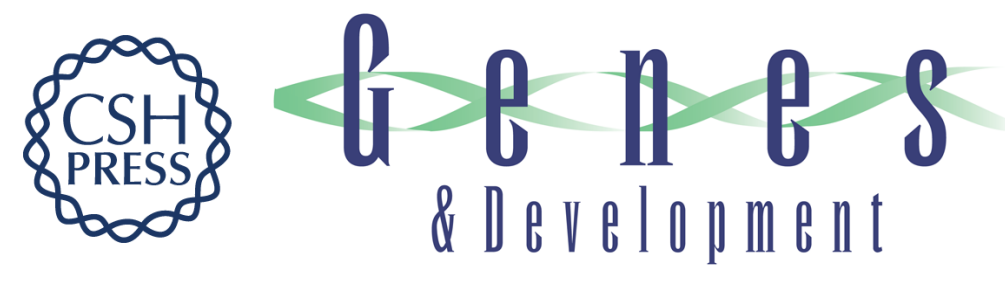

\section{G9a/GLP-dependent histone H3K9me2 patterning during human hematopoietic stem cell lineage commitment}

Xiaoji Chen, Kyobi Skutt-Kakaria, Jerry Davison, et al.

Genes Dev. 2012, 26: originally published online October 26, 2012

Access the most recent version at doi:10.1101/gad.200329.112

\section{Supplemental http://genesdev.cshlp.org/content/suppl/2012/10/24/gad.200329.112.DC1 Material}

References This article cites 54 articles, 20 of which can be accessed free at: http://genesdev.cshlp.org/content/26/22/2499.full.html\#ref-list-1

\section{License}

Email Alerting

Receive free email alerts when new articles cite this article - sign up in the box at the top Service

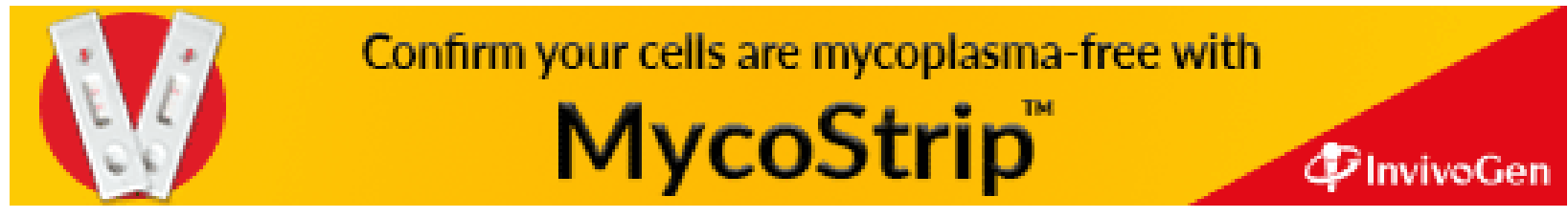

